\title{
MicroRNA expression profiling of human breast cancer identifies new markers of tumor subtype Cherie Blenkiron ${ }^{*^{*}+\sharp \S}$, Leonard D Goldstein ${ }^{\varkappa^{*}+\uparrow}$, Natalie P Thorne ${ }^{*+\uparrow}$,

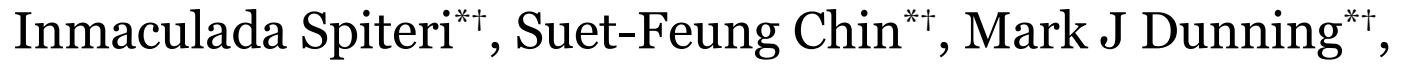 Nuno L Barbosa-Morais ${ }^{* \dagger}$, Andrew E Teschendorff ${ }^{* \dagger}$, Andrew R Green ${ }^{¥}$, Ian O Ellis ${ }^{\ddagger}$, Simon Tavaré ${ }^{*+\uparrow}$, Carlos Caldas ${ }^{*+}$ and Eric A Miska ${ }^{\ddagger \S}$
}

\begin{abstract}
Addresses: *Cancer Research UK, Cambridge Research Institute, Li Ka-Shing Centre, Robinson Way, Cambridge CB2 oRE, UK. ${ }^{\dagger}$ Department of Oncology, University of Cambridge, Hills Road, Cambridge CB2 2XZ, UK. *Wellcome Trust/Cancer Research UK Gurdon Institute, University of Cambridge, The Henry Wellcome Building of Cancer and Developmental Biology, Tennis Court Rd, Cambridge CB2 1QN, UK. $\S$ Department of Biochemistry, University of Cambridge, Tennis Court Rd, Cambridge CB2 1GA, UK. "Department of Applied Mathematics and Theoretical Physics, University of Cambridge, Centre for Mathematical Sciences, Wilberforce Road, Cambridge CB3 oWA, UK. ${ }^{\sharp}$ Department of Histopathology, School of Molecular Medical Sciences, University of Nottingham, Nottingham NG5 1PB, UK.
\end{abstract}

$\bowtie$ These authors contributed equally to this work.

Correspondence: Carlos Caldas. Email: cc234@cam.ac.uk. Eric A Miska. Email: eam29@cam.ac.uk

Published: 8 October 2007

Genome Biology 2007, 8:R214 (doi:10.1 I86/gb-2007-8-10-r214)

The electronic version of this article is the complete one and can be found online at http://genomebiology.com/2007/8/I0/R2 I4
Received: 5 June 2007

Revised: 22 August 2007

Accepted: 8 October 2007

(C) 2007 Blenkiron et al.; licensee BioMed Central Ltd.

This is an open access article distributed under the terms of the Creative Commons Attribution License (http://creativecommons.org/licenses/by/2.0), which permits unrestricted use, distribution, and reproduction in any medium, provided the original work is properly cited.

\begin{abstract}
Background: MicroRNAs (miRNAs), a class of short non-coding RNAs found in many plants and animals, often act post-transcriptionally to inhibit gene expression.

Results: Here we report the analysis of miRNA expression in 93 primary human breast tumors, using a bead-based flow cytometric miRNA expression profiling method. Of 309 human miRNAs assayed, we identify 133 miRNAs expressed in human breast and breast tumors. We used mRNA expression profiling to classify the breast tumors as luminal $A$, luminal $B$, basal-like, HER2+ and normal-like. A number of miRNAs are differentially expressed between these molecular tumor subtypes and individual miRNAs are associated with clinicopathological factors. Furthermore, we find that miRNAs could classify basal versus luminal tumor subtypes in an independent data set. In some cases, changes in miRNA expression correlate with genomic loss or gain; in others, changes in miRNA expression are likely due to changes in primary transcription and or miRNA biogenesis. Finally, the expression of DICERI and AGO2 is correlated with tumor subtype and may explain some of the changes in miRNA expression observed.
\end{abstract}

Conclusion: This study represents the first integrated analysis of miRNA expression, mRNA expression and genomic changes in human breast cancer and may serve as a basis for functional studies of the role of miRNAs in the etiology of breast cancer. Furthermore, we demonstrate that bead-based flow cytometric miRNA expression profiling might be a suitable platform to classify breast cancer into prognostic molecular subtypes. 


\section{Background}

MicroRNAs (miRNAs) were discovered in Caenorhabditis elegans during studies of the control of developmental timing [1-5]. miRNAs are approximately 22-nucleotide non-coding RNAs that are thought to regulate gene expression through sequence-specific base-pairing with target mRNAs [6]. To date, thousands of miRNAs have been identified in organisms as diverse as roundworms, flies, fish, frogs, mammals, flowering plants, mosses, and even viruses, using genetics, molecular cloning and predictions from bioinformatics [7-16]. The human genome encodes at least 474 miRNA genes [17,18].

miRNAs are transcribed as long RNA precursors (pri-miRNAs), which are processed in the nucleus by the RNase III enzyme complex Drosha-Pasha/DGCR8 to form the approximately 70-base pre-miRNAs [19-23]. Pre-miRNAs are exported from the nucleus by Exportin-5 [24], processed by the RNase III enzyme Dicer, and incorporated into an Argonaute-containing RNA-induced silencing complex (RISC) [25]. Within the silencing complex, miRNAs pair to the messages of protein-coding genes, usually through imperfect base-pairing with the 3 '-untranslated region (3'UTR), thereby specifying the post-transcriptional repression of these target mRNAs $[6,26]$. Binding of the silencing complex causes translational repression [27-29] and/or mRNA destabilization, which is sometimes through direct mRNA cleavage $[30,31]$ but usually through other mechanisms [32-36].

The function of human miRNAs is largely unknown. However, studies in roundworms, flies, fish and mice have demonstrated important roles for miRNAs in animal development [37]. miRNA target predictions suggest important roles for miRNAs in humans. Because many mRNAs have been under selective pressure to preserve pairing to a six nucleotide sequence in the $5^{\prime}$ region of the miRNA known as the miRNA seed (nucleotides 2-7), targets of metazoan miRNAs can be predicted by searching for conserved matches to the seed region [38-42]. In humans, at least $10 \%$ of the protein-coding mRNAs might be conserved targets of miRNAs [38,39,41-49].

Despite their recent discovery, strong links between miRNAs and human cancer are emerging. Initial observations in roundworms and flies suggested possible connections between miRNAs and proliferation defects [50]. More recently, it was shown that the human miRNAs miR-15a and miR-16-1 map to a region on 13q14 that is often deleted in Bcell chronic lymphocytic leukemias (CLL) and that miR-15a and miR-16-1 are frequently deregulated in CLL patients [51]. A second study found that miR-143 and miR-145 expression levels were reduced in adenomatous and cancer stages of colorectal neoplasia [52]. Subsequently, a number of studies, using a range of techniques, including miRNA cloning, quantitative PCR, microarrays and bead-based flow cytometric miRNA expression profiling [53-56], demonstrated that miRNA expression is deregulated in many human cancers.
A number of miRNAs were found to have oncogenic potential. For example, the mir-17 miRNA cluster cooperates with the oncogene Myc to induce tumors in a mouse model [57] and miR-372 and miR-373 were found to cooperate with RAS in an in vitro assay [58]. miRNAs might also act as tumor suppressors. For example, deregulation of the oncogene $R A S$ and HMGA2 by loss of regulation through the let-7 family of miRNAs might contribute to human cancer [59-61]. It is unclear how miRNAs might be deregulated in cancer; however, it has been observed that many human miRNAs lie within cancer associated genomic regions, that is, areas of loss, gain or rearrangement of the DNA in tumors [62]. However, transcriptional or post-transcriptional regulation of miRNAs in cancer has also been proposed $[63,64]$.

The molecular classification of human tumors using mRNA microarray profiling is an area of intense research. A number of classifiers have been developed for human breast tumors, including the use of expression signatures as prognostic tools [65-75]. One of these classifiers can be used as a single sample predictor (SSP) to assign individual samples to one of five breast tumor subtypes: luminal A, luminal B, basal-like, HER2+ and normal breast-like [65,69,70,76].

Two recent studies have shown that a number of miRNAs are deregulated in human breast cancer [77,78]. A third study found that a number of miRNAs were differentially expressed in breast tumor biopsies and that miRNA expression correlated with HER2 and estrogen receptor (ER) status [79].

This study represents the first integrated analysis of miRNA expression, mRNA expression and genomic changes in human breast cancer and may serve as a basis for functional studies of the role of miRNAs in the etiology of breast cancer. Furthermore, we demonstrate that bead-based flow cytometric miRNA expression profiling might be a suitable platform to classify breast cancer into prognostic molecular subtypes. This potential will need to be addressed in a prospective study.

\section{Results \\ There are 133 miRNAs expressed in normal human breast and primary human breast cancer}

To generate a comprehensive set of miRNA expression profiles for primary human breast cancer we selected 99 primary human tumors, 5 normal breast samples and 33 breast cancer cell lines for miRNA expression profiling. Tumor samples were fresh-frozen and collected from Nottingham City Hospital Tumor Bank and are representative with regard to tumor subtypes and clinical parameters [80-82]. For miRNA profiling we chose a bead-based flow-cytometric miRNA expression platform, which has recently been developed and was found to have several advantages over glass-slide microarray profiling, including increased specificity [56]. We developed this platform further to include 333 probes for 309 unique 
human miRNAs based on the miRNA repository miRBase 8.1 $[17,18]$. miRNA labeling included RNA size selection using native polyacrylamide gels, ensuring that only mature miRNAs were assayed.

Using this miRNA expression platform we analyzed a total of 137 samples in 168 assays. Assays for 119 of these 137 samples (87\%) passed our quality control, including 93 primary tumor samples, 5 normal breast samples and 21 cell lines (Additional data file 1). We detected the expression of 137 miRNAs in this sample set, 133 of which we detected in normal breast or breast tumors. We included a number of replicate probes and technical replicate samples and found that results were reproducible (Additional data files 5 and 6). For a subset of miRNAs and a subset of samples we also performed quantitative RT-PCR to independently assess miRNA expression (Additional data file 7). While there is generally good correlation between miRNA expression on both platforms, we do observe probe-specific differences. Sample quantity did not permit validation of miRNA expression using northern blotting; however, the bead-based flow-cytometric miRNA expression platform had been validated using northern blotting previously [56].
Unsupervised hierarchical clustering of miRNA expression clearly separated cell lines from both normal breast and tumor samples and suggested that miRNA expression in cell lines is largely deregulated (Figure 1a). We did not observe a perfect separation of normal and tumor samples, as has been described before for primary human tumors [56]. However, as our study was focused on tumor subtypes, we profiled only a small number of normal breast samples. As we found major differences in miRNA expression between primary human tissue and cell lines, we excluded cell lines from subsequent analyses. Unsupervised clustering of the tumor samples revealed striking differences in miRNA expression between ER- and ER+ tumors (Figure 1b).

\section{MicroRNAs are differentially expressed between molecular breast tumor subtypes with clinical implications}

Next we tested if miRNAs are differentially expressed among breast cancer subtypes. To identify the molecular subtypes of our tumor samples we used a single sample predictor (SSP), which classifies breast tumors into five subtypes: luminal A, luminal B, basal-like, HER2+ and normal-like [65,69,70,76]. In addition to differences in mRNA expression profiles, these

\section{(a)}

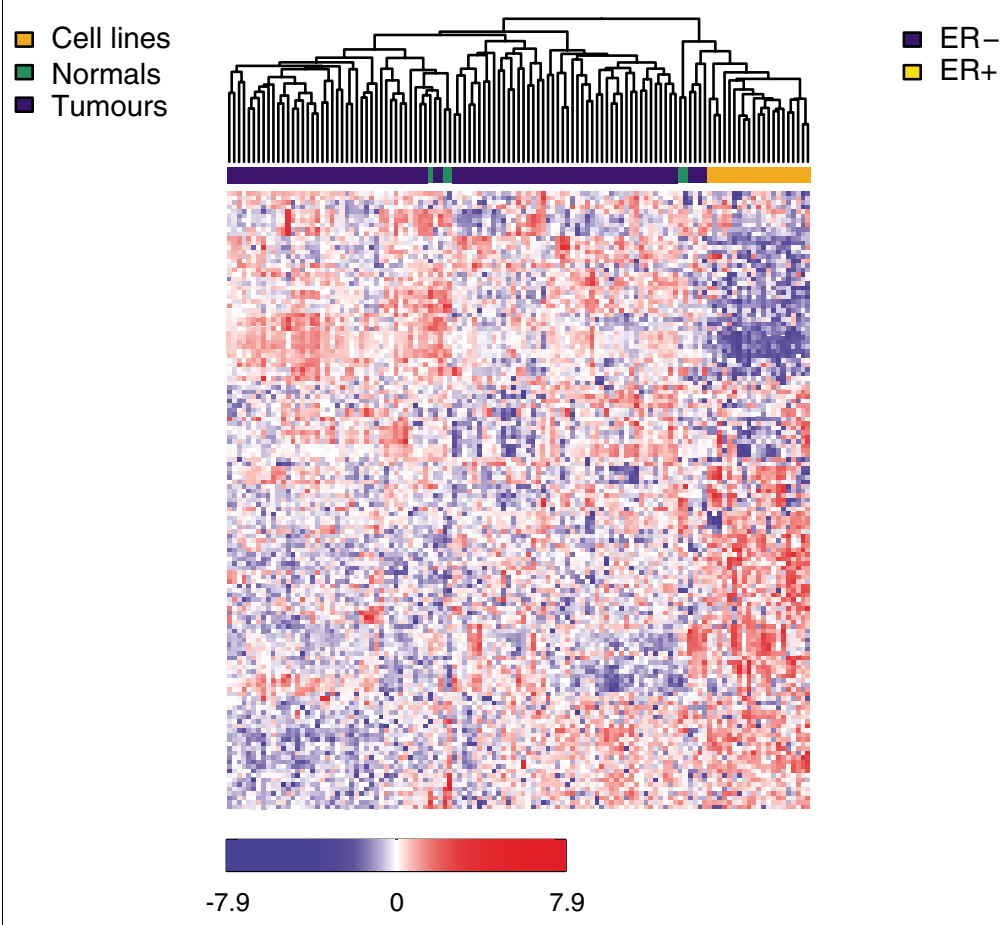

(b)

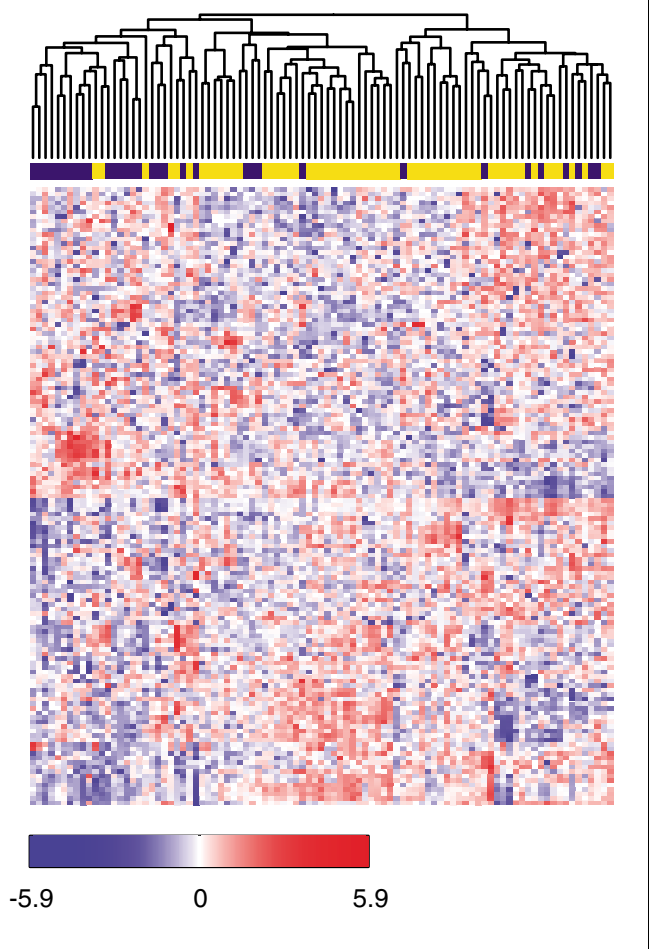

Figure I

Unsupervised hierarchical clustering (Pearson correlation, average linkage) over 137 detected miRNAs. Heatmap colors represent relative miRNA expression as indicated in the color key. (a) Clustering of 21 cell lines (orange), 5 normal breast samples (green) and 93 primary tumors (blue). (b) Clustering of 93 primary tumors with ER status as shown. 
(a)

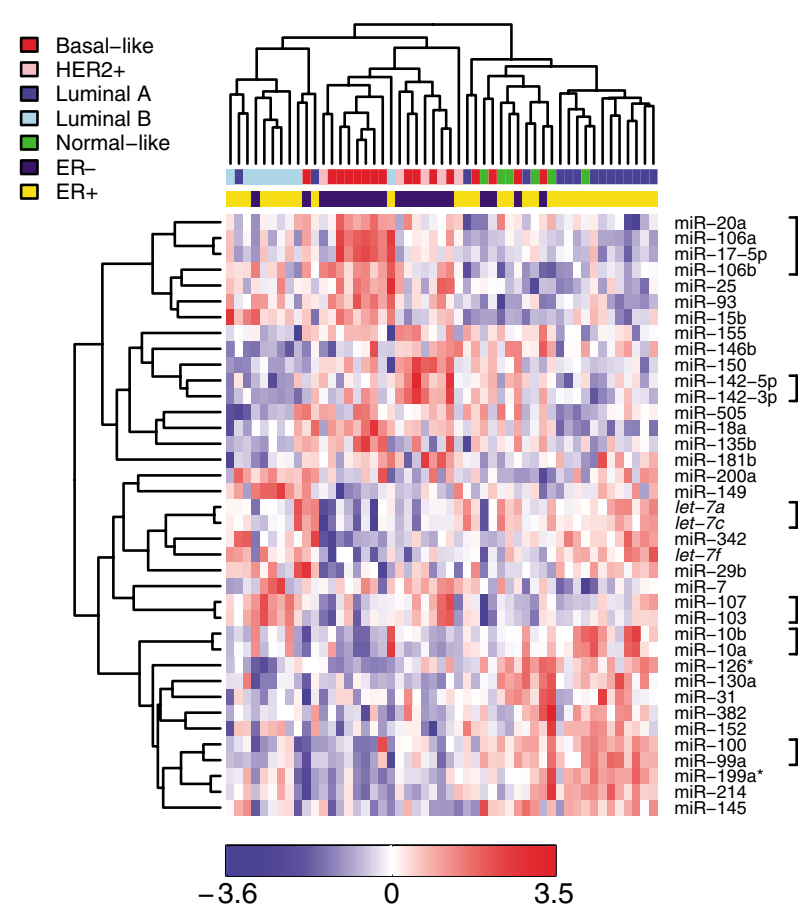

(b)

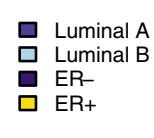

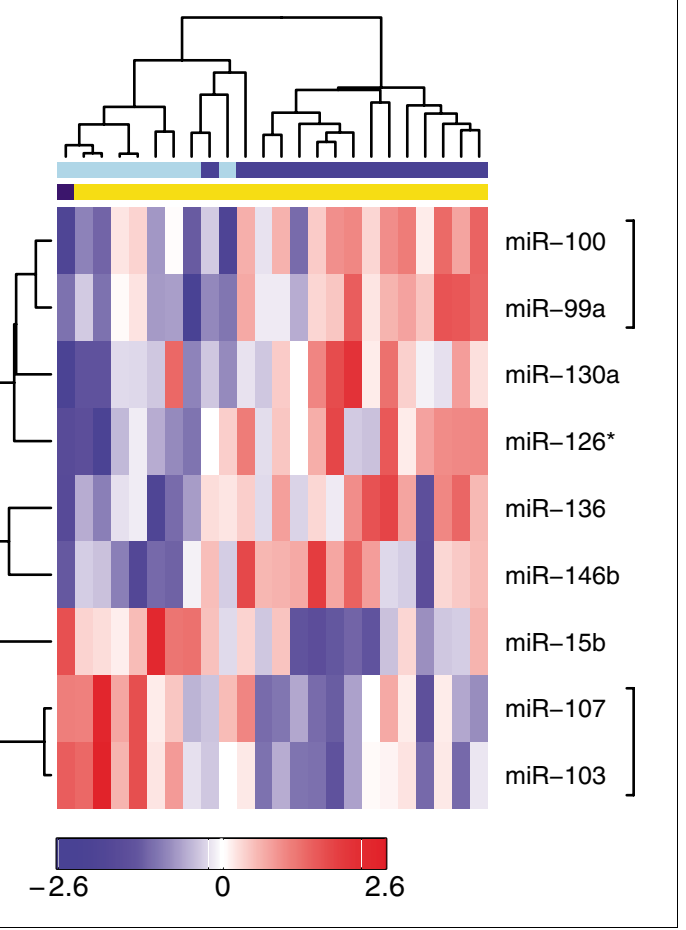

Figure 2

Supervised hierarchical clustering over selected miRNAs (Pearson correlation, average linkage). Heatmap colors represent relative miRNA expression as indicated in the color key for each panel. Brackets in the right margin indicate members of the same miRNA family. (a) Clustering of $5 \mathrm{I}$ tumor samples that could be classified as basal-like (red), HER2+ (pink), luminal A (dark blue), luminal B (light blue) or normal-like (green) over 38 miRNAs with Benjamini-Hochberg adjusted Kruskal-Wallis $p<0.05$. (b) Clustering of 24 tumor samples classified as luminal A (dark blue) or luminal B (light blue) over 9 miRNAs with Benjamini-Hochberg adjusted Wilcoxon $p<0.05$.

tumor subtypes also display distinct clinicopathological characteristics, including different survival rates (Additional data files 8 and 9). For example, the basal-like and HER2+ tumors are less differentiated and more aggressive and the luminal A and luminal B tumors are mostly ER+ with good and poor clinical outcome, respectively. Based on Agilent and Illumina mRNA expression data for 86 of our tumor samples [83] (unpublished results) we were able to classify 51 of the 93 tumor samples as 16 basal-like, 15 luminal A, 9 luminal B, 5 HER2+ and 6 normal-like tumors (Additional data file 1). miRNAs that were found to be differentially expressed in the tumor subtypes are shown in Figure 2a,b. miRNAs that are part of the same family show highly correlated expression. For example, the nine miRNAs that were found to be differentially expressed between luminal A and luminal B tumors represent seven miRNA families (Figure $2 b$ ).

Given the large number of miRNAs differentially expressed between molecular subtypes, we investigated the predictive potential of miRNAs in an independent test set. Using all 137 expressed miRNAs, we performed a model-based discriminant analysis [84] for the 16 basal-like and 15 luminal A tumors, the two largest subtype groups in our study (Addi- tional data file 1). As we aimed to distinguish between molecular subtypes, we required a test set of samples with both miRNA and mRNA expression data available. The beadbased miRNA expression data in Lu et al. [56] included 11 breast tumor samples with corresponding Affymetrix gene expression data published in [56,85]. To our knowledge, no other studies with miRNA and mRNA data on breast tumor samples have been published. Based on the gene expression profiles and the SSP, six tumor samples could be assigned to molecular subtypes, three of which were classified as basallike, two as luminal A and one as HER2+ (Additional data files 1, 14 and 19). Using the discriminator derived from our miRNA data, all three basal-like and two luminal A tumors in the independent miRNA data set were classified in concordance with their SSP molecular subtype classification.

\section{A number of miRNAs are associated with clinicopathological factors}

We next assessed associations between individual miRNAs, molecular tumor subtypes and clinicopathological factors (Figure 3 and Additional data file 18). We tested for statistically significant associations with tumor characteristics such as molecular subtype, grade, stage, vascular invasion, ER sta- 


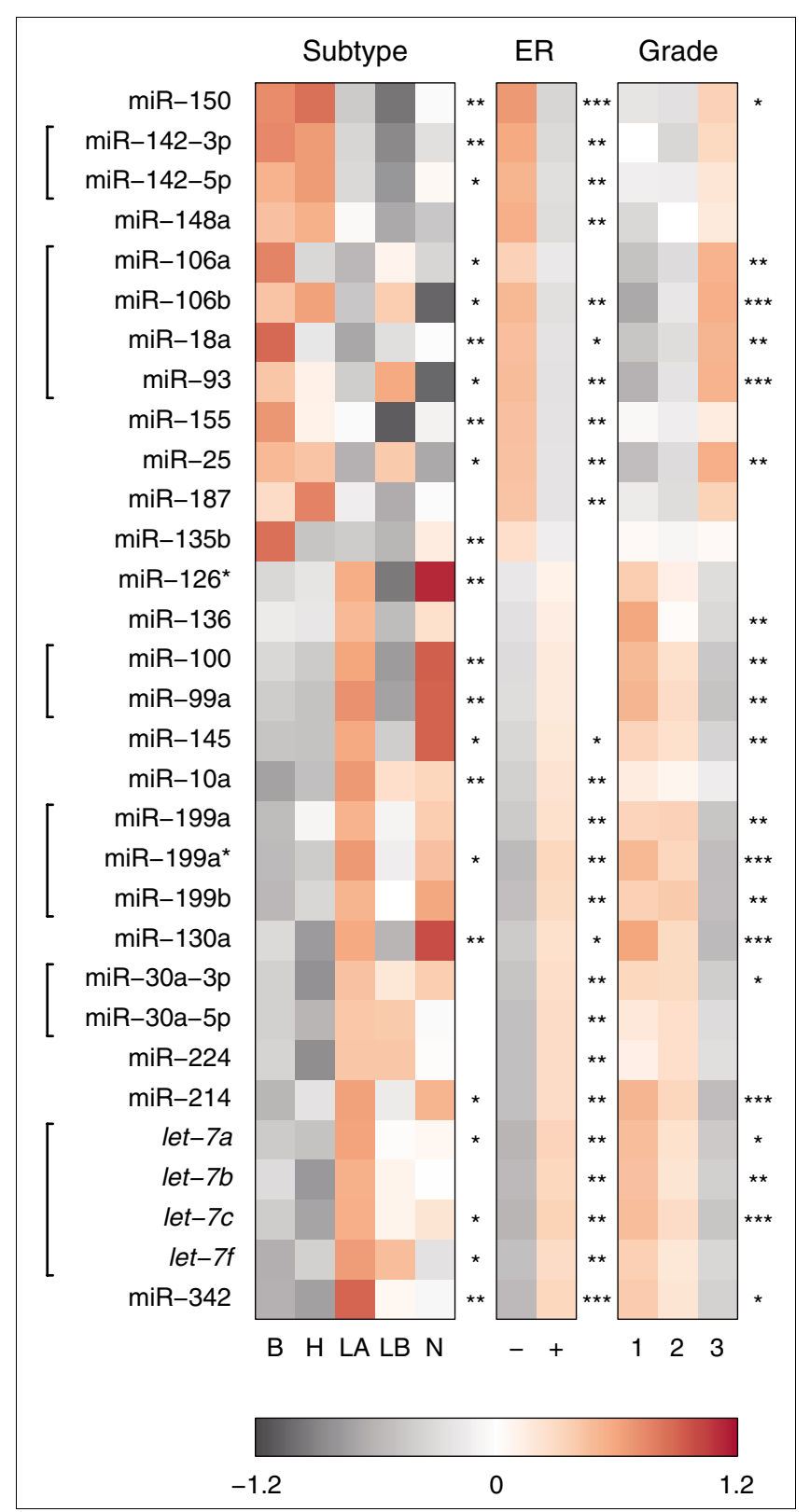

Figure 3

Association of individual miRNAs and tumor subtype or clinicopathological factors. Shown are 31 miRNAs and three factors with at least one association at adjusted $p<0.01$. Differential expression was assessed by a non-parametric Wilcoxon rank sum test for comparison between two groups or a non-parametric Kruskal-Wallis test for comparison between multiple groups. To address the issue of multiple testing for the same factor, $p$ values were adjusted by Benjamini and Hochberg's method [102]. Heatmap colors represent relative miRNA expression as shown in the color key. The expression values for a given sample group of interest were summarized by their mean. Brackets in the left margin indicate members of the same miRNA family. Significance levels are shown in the right margins: $*$ adjusted $p<0.05$; $* *$ adjusted $p<0.0 \mathrm{I}$; *** adjusted $p<0.00$ I. Abbreviations for subtype: $B$, basal-like; H, HER2+; LA, luminal $A$; LB, luminal $B ; N$, normal-like. tus, Nottingham Prognostic Index (NPI) as well as TP53 status as determined by mutation screening and HER2 status assessed by immunohistochemistry (unpublished results). Figure 3 summarizes data for those 31 miRNAs and clinical factors for which there are significant associations at an adjusted $p$ value less than 0.01 (Materials and methods). These 31 miRNAs represent 20 distinct miRNA families. Most of these miRNAs are expressed in the less aggressive, grade 1 , ER+ samples. However, some miRNAs are expressed in the more aggressive grade 3/ER- tumors. We did not find any strong associations with stage, vascular invasion, NPI, TP53 or HER2 status.

\section{Chromosomal loss or gain cannot explain the majority of changes in miRNA expression}

Given the changes in miRNA expression we observed, it is important to ask how these changes come about. We first tested if the changes in miRNA expression are likely due to chromosomal loss, gain or amplification as inferred from array comparative genomic hybridization (CGH) data. For 82 of the 93 tumor samples we analyzed for miRNA expression, we performed array CGH analysis based on gene centric oligonucleotide microarrays $[86,87]$. For each miRNA locus that was identified as altered in any of the samples, we performed separate non-parametric Wilcoxon rank sum tests to assess differences in expression between samples with loss, gain or amplification compared to samples without changes.

We found that in many cases expression differences could not be explained by any genome alterations detected by our array CGH data (Figure 4). The expression of 17 out of 129 mature miRNAs transcribed from genomic regions with an observed aberration correlated with genomic changes at 15 distinct chromosomal loci ( $p<0.01$ ). For miR-33 and miR-320, we found strong associations between miRNA expression and genomic alterations ( $p<0.001)$, suggesting chromosomal change is a possible mechanism for mis-expression of these genes in primary human breast cancers. We also identified miRNA clusters whose changes in expression were correlated with copy number, for example, for miR-3ob and miR-3od at C8q24.22 $(p<0.001)$ and miR-15b and miR-16-2 at C3q26.1 $(p<0.05)$.

\section{Expression of clustered miRNAs is coordinated}

We noticed that miRNA clusters are often expressed coordinately in our sample set. For example, miR-106b, miR-93 and miR-25 situated on C7q22.1 are highly expressed in highgrade tumors. To further examine this phenomenon, we calculated the pairwise Pearson correlation of expression between miRNAs on the same chromosome and strand. We observed an abrupt drop in correlation of miRNA expression for pairs of miRNAs that were more than $50 \mathrm{~kb}$ apart (Additional data file 12). These observations agree well with what has been observed earlier in human tissue samples [88]. We therefore used a distance of $50 \mathrm{~kb}$ as a cut-off to identify 56 intergenic or gene-resident spatial clusters, 44 of which are 


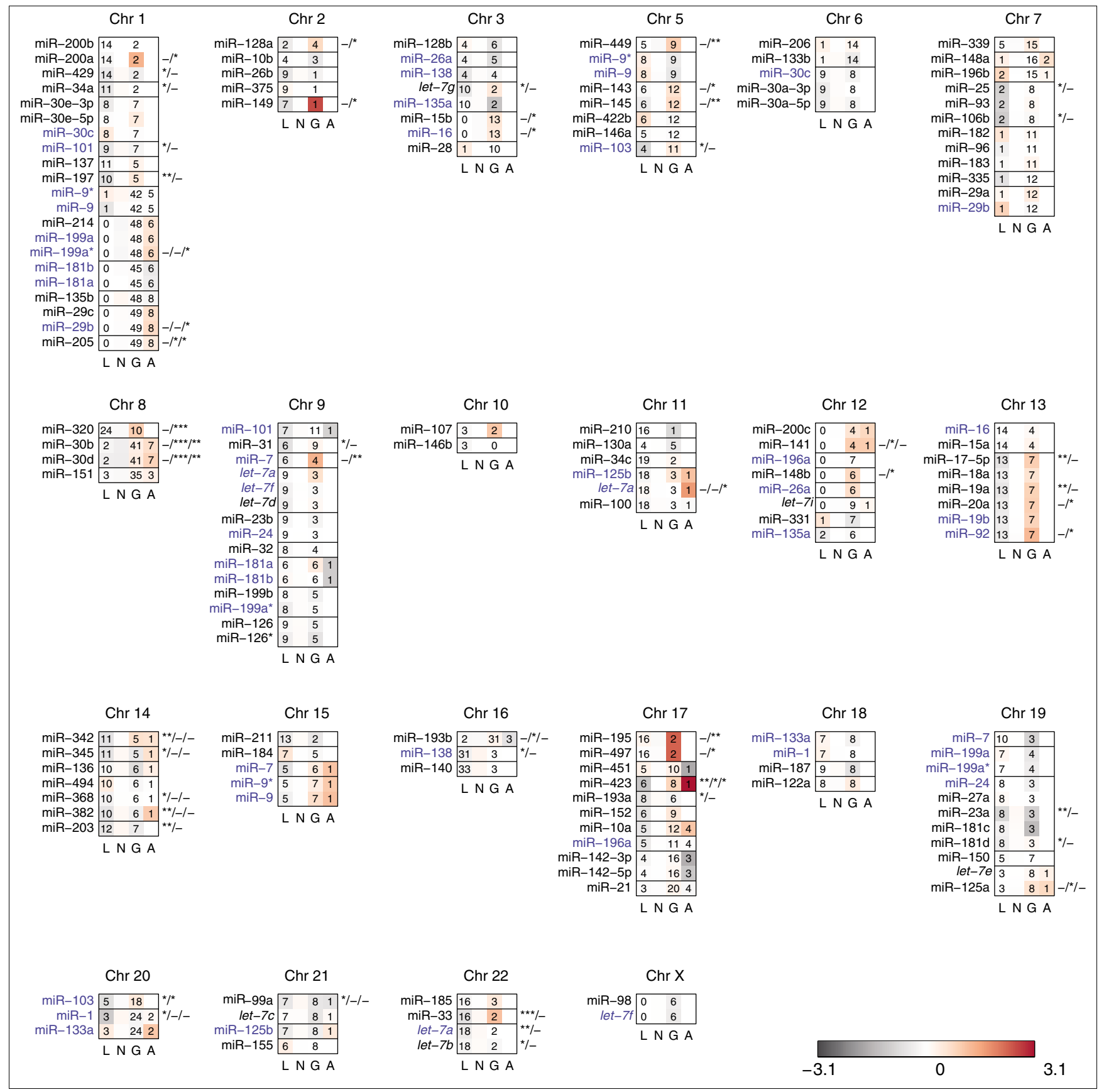

\section{Figure 4}

Association of miRNA expression and DNA copy number. miRNAs mapping to regions of genomic aberration were plotted according to chromosome and genomic location. Heatmap colors represent relative miRNA expression as shown in the color key. Expression values for samples with genomic loss $(L)$, unaltered samples $(N)$, samples with genomic gain $(G)$ and amplification $(A)$ were summarized by their mean, respectively, with numbers of samples as indicated. miRNAs transcribed from multiple loci are indicated in blue. Adjacent miRNAs not separated by a black line are less than $50 \mathrm{~kb}$ apart. Significance levels correspond to unadjusted $p$ values obtained by a non-parametric Wilcoxon rank sum test $(* p<0.05$, $* * p<0.01$, $* * * p<0.00 \mathrm{I})$. Given the high dependence of the performed tests, $p$ values were not adjusted for multiple testing.

represented in the set of 137 miRNAs detected in our sample set. Interestingly, 26 of 31 clusters for which expression data from multiple stem-loop regions were available show corre- lated expression with $\mathrm{r}>0.4$ (Figure 5 and Additional data file 13). For example, the miR-15 and miR-16 family are expressed from two clusters at chromosomes $3 q$ and $13 q$, 
which are both highly correlated ( $\mathrm{r}>0.8$ ). In many cases these correlations are likely due to shared regulatory elements or polycistronic expression of several miRNAs from a single primary transcript [88].

\section{A number of miRNA genes are co-regulated as part of larger domains}

Since only 17 of the 137 miRNAs expressed in our samples showed changes in their expression associated with detected chromosomal abnormalities, changes in miRNA expression may be due to changes in transcription of primary miRNA transcripts. We showed above that miRNA clusters are expressed coordinately. We therefore asked if expression levels of miRNAs that are intronic are correlated with the expression of their host gene, as this suggests changes in primary transcription rates. To test this hypothesis, we compared miRNA expression data with Illumina mRNA expression data for our tumor sample set (unpublished results; Additional data file 13). We only detected correlations for seven miRNA host gene pairs ( $r>0.4$ ), suggesting that changes in miRNA expression in our tumor sample set are not generally linked to host gene expression (Table 1). These seven miRNA host gene pairs were miR-30e-5p/NFYC, miR149/GPC1, miR-25/93/106b/MCM7, miR-342/EVL and miR-99a/C21orf34.

For miRNA genes that are intergenic, we performed a similar comparison using the most proximal probes (within $50 \mathrm{~kb}$ ) from the Illumina platform as these probes might correspond to primary miRNA transcripts (Additional data file 13). Only 23 out of $243 \mathrm{miRNA} /$ proximal probe pairs at 11 distinct loci correlated in expression ( $r>0.4$; Table 1 ). Some of these miRNAs have proximal probes that are very close and likely represent primary miRNA transcripts. For example, miR-205 expression is highly correlated with the proximal probe for transcript $N P C-A-5$ ( $\mathrm{r}>0.75)$. One striking example of correlated expression of miRNAs and proximal probes was miR10a, which is part of the $H O X B$ cluster (C17q21.32), where Illumina probe data suggest the co-regulation of a region from $H O X B 2$ to $H O X B 6$ including miR-10a (Table 1).

\section{Some changes in miRNA expression may be due to changes in miRNA biosynthesis}

As genomic changes and transcriptional regulation of miRNA expression do not explain the changes in miRNA expression we observed in human breast cancers, post-transcriptional regulation of miRNA expression has to be considered. Indeed, recent studies suggested that primary miRNA processing might be deregulated in human cancer [64,89,90]. Therefore, we tested whether genes required for miRNA biogenesis are differentially expressed in our breast cancer samples. As we found many changes in miRNA expression across the five clinical tumor subtypes we had defined above (Figure 2), we asked whether DICER1, DROSHA, DGCR8, $A G O 1, A G O 2, A G O_{3}$ or $A G O_{4}$ expression differs among these subgroups. We found significant changes in the expression of DICER1 $(p<0.001)$, which was low in the more aggressive basal-like, HER2+ and luminal B type tumors, and AGO2, which was high in basal-like, HER2+ and luminal B type tumors (Figure 6). We did not find significant changes in the expression of DROSHA, DGCR8, or any of the other AGO genes (Figure 6 and Additional data file 10). We also observed significant changes in AGO2, DICER1 and DROSHA expression in relation to ER status, with $A G O 2$ and DROSHA being higher and DICER1 lower in ER- tumor samples (Figure 6).

The observed deregulation of genes required for miRNA biogenesis may be expected to lead to global changes in miRNA expression. To further investigate this possibility, we utilized an alternative approach to between-sample normalization. For the analyses described previously, sample median centering proved advantageous in removing technical variation between samples without changing trends in differential expression (Additional data files 1 and 4). However, this method necessarily removed any global changes in miRNA expression. Using an alternative normalization based on spike-in controls, similar to the method described in [56], we detected small differences in mean miRNA levels according to ER status with lower mean miRNA expression in ER- tumors (Figure 6d).

\section{Discussion}

Using an innovative bead-based miRNA expression profiling method we have determined the expression profile for 309 miRNAs in primary human breast cancer. We found that miRNA expression classified molecular tumor subtypes. Furthermore, a number of individual miRNAs were associated with clinicopathological factors. Changes in miRNA expression were complex and were likely due to genomic loss

\footnotetext{
Figure 5 (see following page)

Expression of clustered miRNAs is coordinated. Shown are pairwise scatter plots of expression values for mature miRNAs transcribed from genomic regions within $50 \mathrm{~kb}$ of each other. (a) miR-I5a, miR-I5b and miR-I6 transcribed from two intronic clusters at C3q26.I (SMC4LI) and CI3qI4.3 (DLEU2). (b) miR-25, miR-93 and miR-106b transcribed from an intronic cluster at C7q22.I (MCM7). (c) miR-199a, miR-I99a*, miR-I99b and miR-2I4 transcribed from one intergenic cluster at Clq24.3 and two intergenic stem-loops at C9q34.II and CI9p I3.2. Pearson correlation coefficients ( $r$ ) and data points shown are based on samples with available array CGH data and no identified genomic loss or gain at the relevant locus (Additional data file I). Genome plots are drawn to scale as shown in the legend (bottom right), except where missing regions are indicated by vertical bars. Positive and negative strands are depicted by the top and bottom plots, respectively. Gene loci and miRNA stem-loop regions are colored in blue and red, respectively. The location of exons is marked by greater line width.
} 
(a)
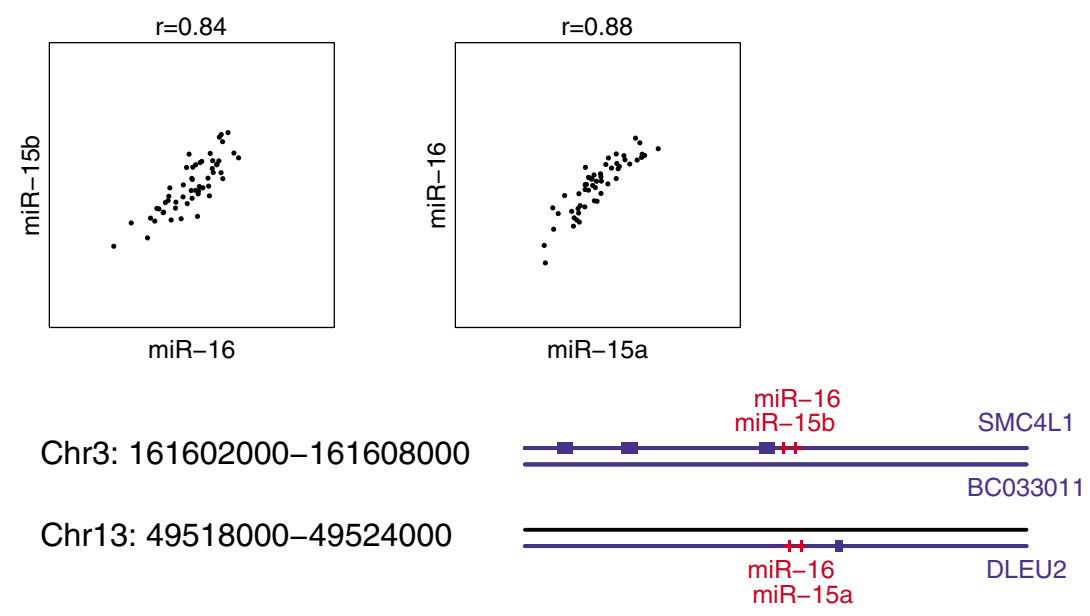

(b)

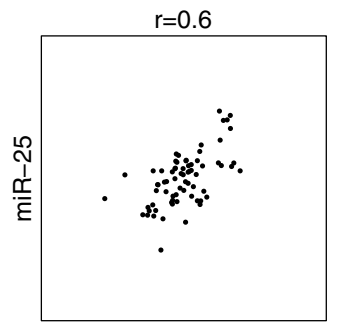

miR-106b

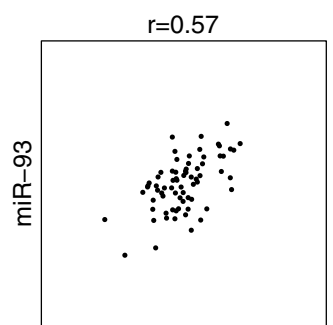

miR-106b

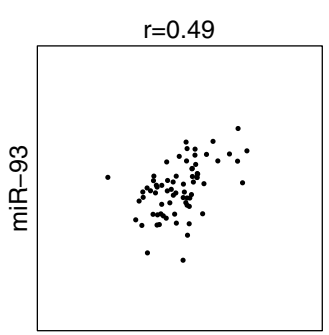

miR-25

Chr7: 99526000-99533000

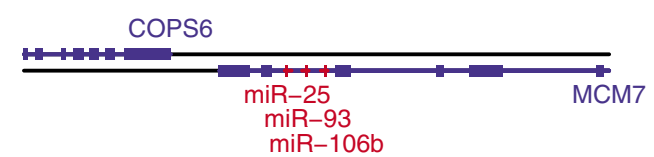

(c)
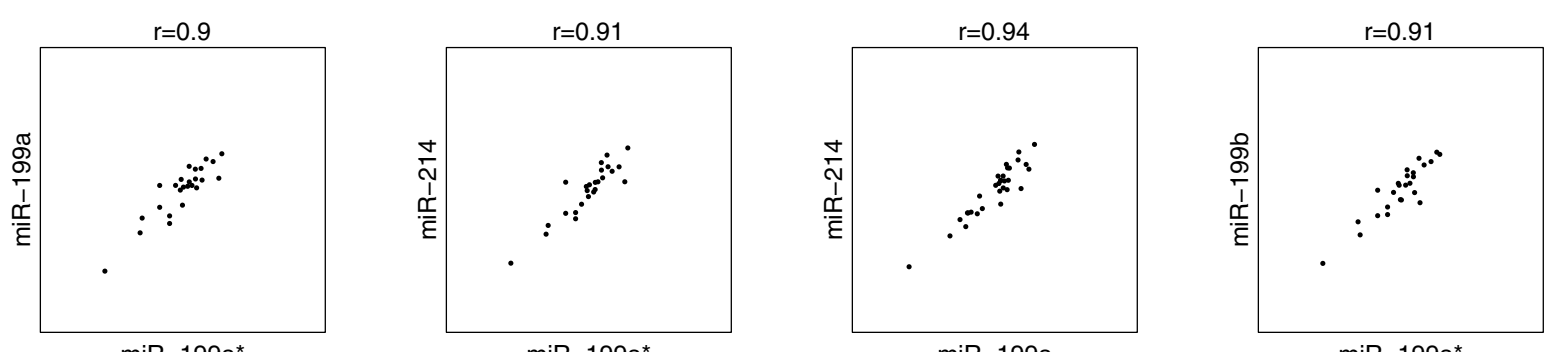

miR-199a*

miR-199a

miR-199a*

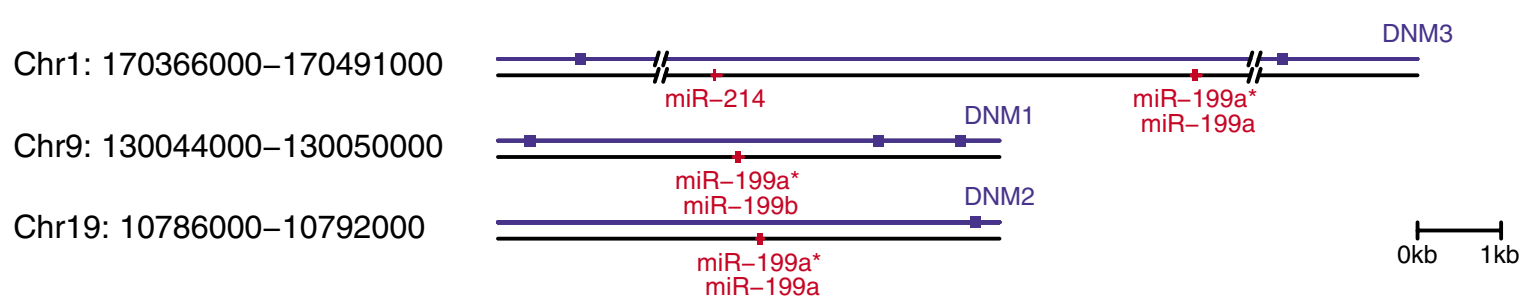

Figure 5 (see legend on previous page) 
Table I

\begin{tabular}{|c|c|c|c|c|c|c|}
\hline \multirow[b]{2}{*}{ miRNA } & \multirow[b]{2}{*}{$\begin{array}{l}\text { Chromosome } \\
\text { position }\end{array}$} & \multicolumn{2}{|c|}{ Host gene } & \multicolumn{3}{|c|}{ Proximal probe } \\
\hline & & Name & $\begin{array}{r}\text { Pearson } \\
\text { correlation }\end{array}$ & Namet & $\begin{array}{r}\text { Pearson } \\
\text { correlation }\end{array}$ & $\begin{array}{r}\text { miRNA/probe } \\
\text { distance }(\mathrm{kb})\end{array}$ \\
\hline miR-I0I & $|p 3| . \mid$ & & & FLJ26232 & 0.4337 & 35.99 \\
\hline miR-30e-5p & Ip34.2 & NFYC & 0.4950 & & & 17.02 \\
\hline miR-I8Ia & Iq31.3 & & & Hs.4973IO & 0.4106 & 19.61 \\
\hline miR-205 & $1 \mathrm{q} 32.2$ & & & NPC-A-5 & 0.7936 & 0.00 \\
\hline \multirow[t]{2}{*}{ miR-IOb } & $2 q 31.1$ & & & HOXDIO & 0.4902 & 30.96 \\
\hline & & & & HOXD8 & 0.4472 & 18.53 \\
\hline miR-I49 & $2 q 37.3$ & GPCI & 0.6567 & & & 11.68 \\
\hline miR-30a-3p & $6 q 13$ & & & BCO40204 & 0.6406 & 16.17 \\
\hline \multirow[t]{2}{*}{ miR-30a-5p } & $6 q 13$ & & & BCO40204 & 0.7091 & 16.17 \\
\hline & & & & C6orfl55 & 0.4995 & 11.12 \\
\hline miR-30c & $6 q 13$ & & & BCO40204 & 0.4566 & 10.30 \\
\hline miR-I06b & $7 q 22.1$ & MCM7 & 0.5157 & & & 1.02 \\
\hline $\operatorname{miR}-25$ & $7 q 22.1$ & MCM7 & 0.4939 & & & 0.59 \\
\hline miR-93 & $7 q 22.1$ & MCM7 & 0.4988 & & & 0.79 \\
\hline miR-I8Ia & $9 q 33.3$ & NR6AI & & $R 08260$ & 0.5913 & 1.51 \\
\hline miR-I8Ib & $9 q 33.3$ & NR6Al & & $R 08260$ & 0.5634 & 2.78 \\
\hline miR-196a & $12 q 13.13$ & & & $\mathrm{HOXClO}$ & 0.4914 & 1.75 \\
\hline miR-342 & $14 q 32.2$ & $E V L$ & 0.7208 & & & 34.26 \\
\hline \multirow[t]{7}{*}{ miR-10a } & $17 q 21.32$ & & & Gl_30I5969I & 0.8123 & 0.40 \\
\hline & & & & HOXB6 & 0.8085 & 16.10 \\
\hline & & & & HOXB5 & 0.7150 & 11.48 \\
\hline & & & & НОХВЗ & 0.6908 & 29.79 \\
\hline & & & & HOXB2 & 0.7019 & 36.74 \\
\hline & & & & HOXB4 & 0.6856 & 2.90 \\
\hline & & & & HOXB8 & 0.5937 & 32.43 \\
\hline miR-199a* & $19 p \mid 3.2$ & DNM2 $\ddagger$ & & TMEDI & 0.4111 & 15.22 \\
\hline miR-99a & $2 \mid q 21.1$ & C2 I orf34 & 0.4766 & & & 67.87 \\
\hline miR-I55 & 2 Iq2।.3 & & & $B I C$ & 0.4688 & 0.73 \\
\hline let-7a & $22 q \mid 3.31$ & & & FLJ27365 & 0.5272 & 1.45 \\
\hline let-7b & $22 q 13.31$ & & & FLJ27365 & 0.5732 & 2.38 \\
\hline
\end{tabular}

†Gene symbol, accession number or Illumina probe identifier. $¥$ Gene lies on the opposite strand.

or gain, transcriptional and post-transcriptional regulation and changes in the expression of miRNA biogenesis enzymes. This study forms the basis for developing miRNA expression signatures as diagnostic tools for breast cancer and also furthers our understanding of the role of miRNAs in tumorigenesis.

Two previous studies of miRNA expression in human breast cancer have focused on comparing normal tissues to tumor samples. Here we focused on miRNA expression analysis of a large set of primary human tumors to reveal signatures of tumor subtype. Nevertheless, we also identified 7 out of 24 miRNAs that had previously been associated with breast cancers compared to normal tissues [78] (Additional data file 18).
In addition, we can confirm three of 26 miRNAs that were reported in a separate study [77]. Notably, one miRNA, miR155, is differentially expressed in ER- versus ER+ tumors (Figure 3), overexpressed in breast tumors compared to normal controls $[77,78]$ and additionally other tumor types, suggesting that this miRNA may have diagnostic potential beyond breast cancer [54,91-93]. More recently, a quantitative RT-PCR study of miRNA expression from breast cancer biopsies revealed that miRNA expression classifies ER status [79], which is in agreement with our observations (Figure 1b). Surprisingly, we found little agreement among miRNAs we identified as being associated with clinicopathological factors and miRNAs identified in this context in a previous study [77]. 


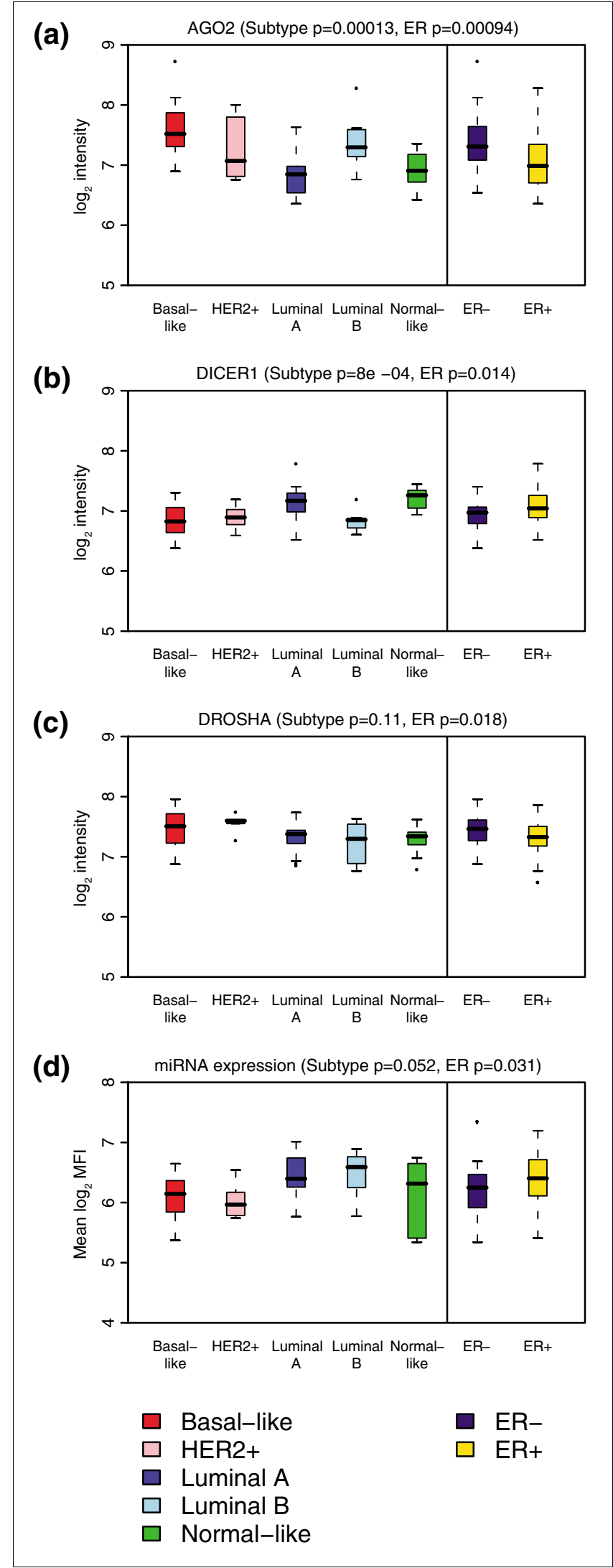

Figure 6
Figure 6

Genes required for miRNA biogenesis are differentially expressed according to molecular subtype and ER status. Shown are boxplots of Illumina $\log _{2}$ intensities for (a) AGO2 (EIF2C2), (b) DICERI, (c) DROSHA (RNASEN). Data are based on 58 samples that could be classified according to molecular subtype ( 17 basal-like (red), 5 HER2+ (pink), I 8 luminal A (dark blue), 8 luminal B (light blue), 10 normal-like (green)) and 99 samples with known ER status (3I ER- (blue), 68 ER+ (yellow)). (d) Boxplots of mean miRNA expression after control-based normalization. Data are based on $5 \mathrm{I}$ samples that could be classified according to molecular subtype ( 16 basal-like (red), 5 HER2+ (pink), 15 luminal A (dark blue), 9 luminal B (light blue), 6 normal-like (green)) and 93 samples with known ER status (33 ER- (blue), 60 ER+ (yellow)). Black bars indicate the median; boxes interquartile range; whiskers most extreme data points not exceeding 1.5 times the interquartile range; points outliers. $P$ values are based on non-parametric Kruskal-Wallis tests for subtype and Wilcoxon rank sum tests for ER status.

We showed that a large number of miRNAs in our data set are associated with molecular subtypes, and we explored the predictive potential of miRNAs in an independent test set. A model-based discriminant analysis of our training set of 31 basal-like and luminal A samples resulted in the classification of 5 samples from an independent study that was in accordance with gene expression-based molecular subtype classification. Although these results are promising, the test set is too small to allow for a sensible performance assessment of the classifier. However, there are currently no other breast tumor data sets with both mRNA and miRNA expression data publicly available that would allow further validation of miRNAbased molecular subtype classification.

If miRNA expression profiles classify primary breast tumor subtypes, they may prove useful as diagnostic tools in the future and this could be assessed in a prospective study. Bead-based array miRNA profiling may be particularly well suited to assay miRNA expression in large-scale diagnostic trials since it is a high-throughput and cost-effective method $[56,94]$. If miRNAs prove useful for clinical breast cancer diagnosis, they have the additional advantage that, in contrast to most mRNAs, they are long-lived in vivo [35] and very stable in vitro [95], which might be critical in a clinical setting and allow analysis of paraffin-embedded samples.

We found that the differences in miRNA expression we observed are likely not due to genomic loss or gain (Figure 4). Therefore, we investigated the regulation of miRNA expression at the transcriptional and post-transcriptional level (Figure 5 , Table 1). As previously described for normal human tissues [88], we found that the majority of miRNA clusters are co-regulated in human breast tumors. These data are also in agreement with similar observations made in human leukemia samples [96] and support the hypothesis that changes in miRNA expression in human cancer may not be distinct from normal tissue-specific miRNA expression in humans. In some instances, miRNA expression also correlates with host gene expression in the case of intronic miRNAs, or with the expression of larger domains, such as the HOXB cluster 
(Table 1 and Additional data file 13). In these instances, miRNA expression appears to be mainly under transcriptional control.

However, in many cases we observe that miRNA expression is not correlated with host genes or primary miRNA transcripts, suggesting post-transcriptional regulation of miRNA expression. Regulation of miRNA expression at the level of $D R O-$ $S H A$ has previously been proposed for human cancer $[64,90]$. We found that DICER1 expression is significantly downregulated in the more aggressive basal-like, HER2+ and luminal B type tumors. Interestingly, a recent study showed that downregulating DICER1 expression promotes tumorgenesis in vitro and in a mouse lung cancer model [97]. Together, these data suggest that DICER1 deregulation might be involved in the etiology of human breast cancer. In addition, we find that the deregulation of genes in the miRNA biogenesis pathway that we observed is in agreement with a number of independent data sets [98] (Additional data file 11).

Although both mRNA and miRNA expression profiles were found to be informative with regard to tumor subtype, their functional relationship remains unclear. In particular, we were interested to discover if changes in miRNA expression may correlate with changes in mRNA levels of direct targets (Additional data file 1). We considered miRNA families with identical seed (nucleotides 2-7) and mRNAs with conserved seed complementarity in their 3'UTR (Targetscan 3.1) [38]. A number of miRNA families showed differential expression between subtypes for their mean expression profile. We could detect only a few instances of enrichment for down- or upregulation of predicted target mRNAs consistent with changes in miRNA expression, although previous studies of normal human tissue did observe such an enrichment [45,99]. However, these data are consistent with the hypothesis that many miRNAs act at the level of translation rather than mRNA stability.

\section{Conclusion}

To date, many studies of miRNA expression in human cancer have focused only on the deregulation of miRNA expression. Here we integrated the analysis of miRNA expression, mRNA expression and DNA copy number in human breast cancer. Based on a combined analysis of miRNA and mRNA expression data we have identified a number of miRNAs that are differentially expressed between molecular tumor subtypes. In addition, we identified candidate miRNAs that are regulated at the genomic, transcriptional and likely post-transcriptional levels in breast cancer using miRNA, mRNA and array CGH data. Using mRNA expression data, we also found that the expression of genes in the miRNA biogenesis pathway is deregulated in breast cancer. We suggest that further analysis of integrated data sets might help to unravel miRNA-dependent pathways in human breast cancer.

\section{Materials and methods \\ Sample collection}

Primary breast tumor specimens were obtained with appropriate ethical approval from the Nottingham Tenovus Primary Breast Cancer Series (Nottingham City Hospital Tumor Bank, Nottingham, UK). All cases were primary operable invasive breast carcinomas collected from 1990 to 1996. Clinical information, including therapy, has been published previously $[80-83,87]$.

\section{RNA extraction and labeling}

RNA was extracted from primary tumors and cell lines using a standard Trizol (Invitrogen, Carlsbad, CA, USA) protocol, modified by washing the final RNA pellet with $80 \%$ EtOH. Frozen tumors were sectioned on a cryostat prior to homogenization in Trizol. RNA quantity and quality were assessed by Nanodrop (Nanodrop Technologies, Wilmington, DE, USA) and Agilent 2100 bioanalyzer (Agilent Technologies, Santa Clara, CA, USA), respectively.

miRNAs were extracted from $5 \mu \mathrm{g}$ of sample total RNA using denaturing PAGE. Briefly, samples were spiked with three synthetic pre-labeling control RNAs (5'-pCAGUCAGUCAGUCAGUCAGUCAG-3', 5'-pGACCUCCAUGUAAACGUACAA-3', 5'-pUUGCAGAUAACUGGUACAAG-3'; Dharmacon, Lafayette, CO, USA) to control for target preparation efficiency, at 3 fmoles/sample. After purification of 18-26 bp RNAs, adaptors were ligated at the $3^{\prime}$ and $5^{\prime}$ ends using T4 RNA ligase (Fermentas, Burlington, OT, CA), a RNA-DNA hybrid 5'pUUUaaccgegaattccagt-idT-3' (Dharmacon; $\mathrm{X}=$ RNA, $\mathrm{x}=$ DNA, $\mathrm{p}=$ phosphate, idT = inverted [3'-3' bond] deoxythymidine) was ligated to the $3^{\prime}$ end and $5^{\prime}$-acggaattcctcactAAA- $3^{\prime}$ (Dharmacon) was ligated to the 5 ' end using T4 RNA ligase. These bi-ligated products underwent reverse transcription using an adaptor specific primer (M37, 5'-pTACTGGAATTCGCGGTTA-3') and then amplified and labeled using PCR (M37 and M33, 5'-biotin-CAACGGAATTCCTCACTAAA-3'). Amplification was performed on an Eppendorf thermal cycler at $95^{\circ} \mathrm{C}$ for $30 \mathrm{~s}, 50^{\circ} \mathrm{C}$ for $30 \mathrm{~s}$ and $72^{\circ} \mathrm{C}$ for $40 \mathrm{~s}$ for 18 cycles. PCR products were precipitated without glycogen and redissolved in $66 \mu \mathrm{l} 1 \times$ TE buffer containing $1 \mu \mathrm{l}$ of three biotinylated post labeling controls (100 fmols each, FVR506, PTG20210, MRC677).

\section{Bead coupling and hybridization}

Oligonucleotide probes were coupled to color-coded polystyrene beads, allowing the simultaneous detection of about 90 different target oligonucleotides. To obtain expression profiles for 309 miRNAs, we created four distinct sets of beadcoupled miRNA probes. Each sample was hybridized to the four bead sets to generate a complete miRNA profile. Oligos were 5'-amino modified with a 6-carbon linker and conjugated to carboxylated xMAP beads (Luminex, Austin, TX, USA) in 96-well formats following the standard manufacturer's protocol. To generate bead set pools, $3 \mu \mathrm{l}$ of each oligobead conjugate was mixed into $1 \mathrm{ml} 1.5 \times$ TMAC buffer $(4.5 \mathrm{M}$ 
tetramethylammonium chloride, $0.15 \%$ sarkosyl, $75 \mathrm{mM}$ Tris$\mathrm{HCl}$ pH 8.o, 6 mM EDTA). Samples were hybridized in a 96well format with two water-only blanks and at least three bead blanks containing water instead of the labeled sample for use as a background control. We included replicate probes and technical replicate samples across bead sets and sample plates, respectively, to aid quality control and data preprocessing. Hybridization was carried out overnight at $50^{\circ} \mathrm{C}$ with $33 \mu \mathrm{l}$ of the bead pool and $15 \mu \mathrm{l}$ of labeled sample.

Unbound sample was removed from beads by washing with 1 $\times$ TE and re-suspending in $1 \times$ TMAC buffer. SAPE, streptavidin-phycoerythrin, premium grade (Invitrogen) was added to the beads (1:10o dilution) and incubated for 10 minutes at $50^{\circ} \mathrm{C}$ to bind to biotin moieties on the cDNA. Samples were processed on a Luminex 100 machine and median fluorescence intensity values acquired using the StarStation software (ACS, Sheffield, UK).

\section{Computational analysis}

Preprocessing

Median fluorescence intensity values smaller than a threshold of 1 were set equal to 1 , and all values were transformed by taking logs (base 2). Samples with low mean expression were excluded from further analyses (Additional data files 1 and 3). To reduce noise due to absent probes, each probe was required to exceed a $\log _{2}$ median fluorescence intensity value of 6 in at least one sample. Systematic probe effects were median-corrected (Additional data files 1 and 2). Replicate probes were summarized by their mean profile and samples were centered to have zero median. Technical replicate samples were summarized by their mean profile. For a more detailed description of preprocessing please see Additional data file 1 .

\section{Genomic annotation}

miRNA probe sequences were matched against stem-loop sequences in miRBase (release 8.1). Genomic miRNA clusters were identified by requiring any two stem-loops on the same chromosome and strand within $50 \mathrm{~kb}$ to belong to the same clusters (Additional data file 16). A miRNA was defined as gene-resident if its stem-loop is completely contained in the locus of a gene transcript on the same chromosomal strand as annotated in the Known Genes and RefSeq Genes tables obtained from the UCSC Genome Browser (hg18) [100] (Additional data file 17).

\section{Illumina gene expression data}

Illumina gene expression data were processed and summarized in the Illumina BeadStudio software. Analyses of the probe level data were performed using the beadarray Bioconductor package [101]. After quality control, between-array qspline normalization was performed for 112 arrays for 99 samples. Replicate arrays were averaged and expression values were transformed by taking logs (base 2).

\section{Subtype classification}

Each array in the preprocessed Illumina and Agilent [83] gene expression data set was normalized to have zero mean and standard deviation one, and each probe was centered to have zero median. An SSP annotation for Agilent probes was provided in [76]. Detailed information on the SSP annotation for Illumina probes can be found in Additional data files 1 and 15. Multiple probes for the same UniGene cluster ID in either data set were summarized by their median profile. Samples were then assigned to the nearest subtype centroid as determined by Spearman correlation, requiring a minimum correlation of 0.3 . Samples that could be assigned to subtypes based on both Agilent and Illumina expression profiles were classified according to the Illumina assignment (Additional data file 1).

\section{Hierarchical clustering}

Prior to hierarchical clustering, miRNA profiles were standardized to have mean zero and standard deviation one. Clustering was performed with average linkage and Pearson correlation.

\section{Supervised analyses}

Differential expression was assessed by a non-parametric Wilcoxon rank sum test for comparison between two groups or a non-parametric Kruskal-Wallis test for comparison between multiple groups. To address the issue of multiple testing for the same contrast, adjusted $p$ values were obtained by Benjamini and Hochberg's method [102].

\section{Copy-number-driven expression}

For each miRNA stem-loop identified as gained, lost or amplified in any of the samples, separate non-parametric Wilcoxon rank sum tests were performed to assess differences in expression between samples with genomic changes and unaltered samples [103]. $P$ values were not adjusted for multiple testing due to the high level of dependence between the performed tests.

\section{Coexpression of proximal miRNAs and Illumina probes}

For a given chromosome and strand, pairwise Pearson correlation coefficients were calculated for all miRNA probes and those Illumina probes mapping to a host gene or within $50 \mathrm{~kb}$ of a miRNA stem-loop. To account for coexpression caused by DNA copy number changes, correlation coefficients for probe pairs were calculated using only those samples with available array CGH data showing no evidence for aberration at either locus (Additional data file 1).

All analyses were performed in the statistical programming environment R [104] using customized functions and functions available from Bioconductor [105,106] and the MCLUST package [107]. All miRNA expression data have been submitted to the Gene Expression Omnibus (GEO) with accession number GSE7842. 


\section{Abbreviations}

$\mathrm{CGH}$, comparative genomic hybridization; ER, estrogen receptor; miRNA, microRNA; NPI, Nottingham Prognostic Index; SSP, single sample predictor.

\section{Authors' contributions}

$\mathrm{CB}, \mathrm{CC}$ and EAM conceived and designed the study. ARG and IOE provided breast cancer samples and clinical information. $\mathrm{CB}$, IS and SC performed the experiments under the supervision of CC and EAM. The statistical analysis and experimental design were conducted by LDG and supervised by NPT. ST and AET provided statistical advice. MD preprocessed the Illumina gene expression data. NLBM provided the Illumina probe annotation. CB, LDG, NPT, ST, CC and EAM wrote the manuscript.

\section{Additional data files}

The following additional data are available with the online version of this paper. A detailed description of the computational analysis carried out is given in additional data file 1 and a layout of the experimental design is shown in additional data file 2. Additional data on miRNA expression analysis can be found in additional data file 3 (pre-processing), additional data file 4 (normalization), additional data file 5 (replicate probes), additional data file 6 (replicate samples) and additional data file 7 (qRT-PCR validation). Additional data file 8 contains a mRNA expression heatmap for 82 classified samples and 75 intrinsic genes, and additional data file 9 contains a pairwise comparison of Kaplan-Meier survival curves for 74 classified samples with available follow up data. Additional data on differential expression of miRNA processing genes can be found in additional data file 10 (this data set) and additional data file 11 (other data sets). Additional data file 12 shows the correlation of proximal miRNA probes and additional data file 13 shows correlations between miRNA probes and Illumina probes. Additional data file 14 shows a modelbased discriminant analysis for Basal-like and Luminal A tumors. Additional data file 15 contains annotation for the intrinsic gene probe set (single sample predictor). Additional data file 16 lists spatial miRNA clusters, additional data file 17 lists host gene coordinates of intragenic miRNAs and additional data file 18 associations between individual miRNAs, molecular tumor subtypes and clinicopathological factors. Additional data file 19 contains the intrinsic gene probe sets used for the model-based discriminant analysis.

\section{Acknowledgements}

This work was funded by grants from Cancer Research UK to CC, ST and EAM. CB was supported by the UK National Translation Cancer Research Network (NTRAC) and LDG was supported by an EPSRC fellowship. ST is a Royal Society-Wolfson Research Merit Award holder. We would like to thank the Tissue Bank, City Hospital, Nottingham, UK for human breast samples. We thank Sarah Hyland for her work on the TP53 mutation screen and John Marioni for useful discussions on the analysis. We would like to thank the reviewers for exceptionally helpful comments on the manuscript.

\section{References}

I. Ambros V, Horvitz HR: Heterochronic mutants of the nematode Caenorhabditis elegans. Science 1984, 226:409-416.

2. Lee RC, Feinbaum RL, Ambros V: The $C$. elegans heterochronic gene lin-4 encodes small RNAs with antisense complementarity to lin-/4. Cell 1993, 75:843-854.

3. Wightman B, Ha I, Ruvkun G: Posttranscriptional regulation of the heterochronic gene lin- 14 by lin- 4 mediates temporal pattern formation in C. elegans. Cell 1993, 75:855-862.

4. Reinhart BJ, Slack FJ, Basson M, Pasquinelli AE, Bettinger JC, Rougvie AE, Horvitz HR, Ruvkun G: The 21 -nucleotide let-7 RNA regulates developmental timing in Caenorhabditis elegans. Nature 2000, 403:90I-906.

5. Chalfie M, Horvitz HR, Sulston JE: Mutations that lead to reiterations in the cell lineages of C. elegans. Cell I98I, 24:59-69.

6. Bartel DP: MicroRNAs: genomics, biogenesis, mechanism, and function. Cell 2004, I 1 6:28I-297.

7. Arazi T, Talmor-Neiman M, Stav R, Riese M, Huijser P, Baulcombe DC: Cloning and characterization of micro-RNAs from moss. Plant / 2005, 43:837-848.

8. Axtell MJ, Bartel DP: Antiquity of microRNAs and their targets in land plants. Plant Cell 2005, 17:1658-1673.

9. Lagos-Quintana M, Rauhut R, Lendeckel W, Tuschl T: Identification of novel genes coding for small expressed RNAs. Science 200I, 294:853-858.

10. Lau NC, Lim LP, Weinstein EG, Bartel DP: An abundant class of tiny RNAs with probable regulatory roles in Caenorhabditis elegans. Science 200I, 294:858-862.

II. Lee RC, Ambros V: An extensive class of small RNAs in Caenorhabditis elegans. Science 200I, 294:862-864.

12. Lim LP, Glasner ME, Yekta S, Burge CB, Bartel DP: Vertebrate microRNA genes. Science 2003, 299: 1540.

13. Llave C, Kasschau KD, Rector MA, Carrington JC: Endogenous and silencing-associated small RNAs in plants. Plant Cell 2002, 14:1605-1619.

14. Reinhart BJ, Weinstein EG, Rhoades MW, Bartel B, Bartel DP: MicroRNAs in plants. Genes Dev 2002, 16:1616-1626.

15. Watanabe T, Takeda A, Mise K, Okuno T, Suzuki T, Minami N, Imai $\mathrm{H}$ : Stage-specific expression of microRNAs during Xenopus development. FEBS Lett 2005, 579:3।8-324.

16. Pfeffer S, Zavolan M, Grasser FA, Chien M, Russo JJ, Ju J, John B, Enright AJ, Marks D, Sander C, Tuschl T: Identification of virusencoded microRNAs. Science 2004, 304:734-736.

17. Griffiths-Jones S, Grocock RJ, van Dongen S, Bateman A, Enright AJ: miRBase: microRNA sequences, targets and gene nomenclature. Nucleic Acids Res 2006, 34:D I 40-I 44.

18. Griffiths-Jones S: The microRNA Registry. Nucleic Acids Res 2004, 32:DI09-III.

19. Denli AM, Tops BB, Plasterk RH, Ketting RF, Hannon GJ: Processing of primary microRNAs by the Microprocessor complex. Nature 2004, 432:23I-235.

20. Gregory RI, Yan KP, Amuthan G, Chendrimada T, Doratotaj B, Cooch N, Shiekhattar R: The Microprocessor complex mediates the genesis of microRNAs. Nature 2004, 432:235-240.

21. Han J, Lee Y, Yeom KH, Kim YK, Jin H, Kim VN: The DroshaDGCR8 complex in primary microRNA processing. Genes Dev 2004, 18:3016-3027.

22. Landthaler $M$, Yalcin $A$, Tuschl $T$ : The human DiGeorge syndrome critical region gene 8 and its $D$. melanogaster homolog are required for miRNA biogenesis. Curr Biol 2004, 14:2162-2167.

23. Lee Y, Ahn C, Han J, Choi H, Kim J, Yim J, Lee J, Provost P, Radmark $\mathrm{O}$, Kim S, Kim VN: The nuclear RNase III Drosha initiates microRNA processing. Nature 2003, 425:4I5-4I9.

24. Lund E, Guttinger S, Calado A, Dahlberg JE, Kutay U: Nuclear export of microRNA precursors. Science 2004, 303:95-98.

25. Du T, Zamore PD: microPrimer: the biogenesis and function of microRNA. Development 2005, 132:4645-4652.

26. Pillai RS: MicroRNA function: multiple mechanisms for a tiny RNA? Rna 2005, II:1753-176I.

27. Olsen $\mathrm{PH}$, Ambros $\mathrm{V}$ : The lin-4 regulatory RNA controls developmental timing in Caenorhabditis elegans by blocking LIN- 
14 protein synthesis after the initiation of translation. Dev Biol 1999, 216:67|-680.

28. Petersen CP, Bordeleau ME, Pelletier J, Sharp PA: Short RNAs repress translation after initiation in mammalian cells. Mol Cell 2006, 21:533-542.

29. Seggerson K, Tang L, Moss EG: Two genetic circuits repress the Caenorhabditis elegans heterochronic gene lin-28 after translation initiation. Dev Biol 2002, 243:215-225.

30. Yekta S, Shih IH, Bartel DP: MicroRNA-directed cleavage of HOXB8 mRNA. Science 2004, 304:594-596.

31. Mansfield JH, Harfe BD, Nissen R, Obenauer J, Srineel J, Chaudhuri A, Farzan-Kashani R, Zuker M, Pasquinelli AE, Ruvkun G, et al.: MicroRNA-responsive 'sensor' transgenes uncover Hox-like and other developmentally regulated patterns of vertebrate microRNA expression. Nat Genet 2004, 36: 1079-1083.

32. Bagga S, Bracht J, Hunter S, Massirer K, Holtz J, Eachus R, Pasquinelli $A E$ : Regulation by let-7 and lin-4 miRNAs results in target mRNA gegradation. Cell 2005, I 22:553-563.

33. Jing $Q$, Huang $S$, Guth S, Zarubin T, Motoyama A, Chen J, Di Padova $\mathrm{F}$, Lin SC, Gram H, Han J: Involvement of microRNA in AU-rich element-mediated mRNA instability. Cell 2005, 1 20:623-634.

34. Giraldez AJ, Mishima Y, Rihel J, Grocock RJ, Van Dongen S, Inoue K, Enright AJ, Schier AF: Zebrafish MiR-430 promotes deadenylation and clearance of maternal mRNAs. Science 2006, 3 I 2:75-79.

35. Lim LP, Lau NC, Garrett-Engele P, Grimson A, Schelter JM, Castle J, Bartel DP, Linsley PS, Johnson JM: Microarray analysis shows that some microRNAs downregulate large numbers of target mRNAs. Nature 2005, 433:769-773.

36. Wu L, Fan J, Belasco JG: MicroRNAs direct rapid deadenylation of mRNA. Proc Natl Acad Sci USA 2006, 103:4034-4039.

37. Alvarez-Garcia I, Miska EA: MicroRNA functions in animal development and human disease. Development 2005, 132:4653-4662.

38. Lewis BP, Burge CB, Bartel DP: Conserved seed pairing, often flanked by adenosines, indicates that thousands of human genes are microRNA targets. Cell 2005, 120:15-20.

39. Lewis BP, Shih IH, Jones-Rhoades MW, Bartel DP, Burge CB: Prediction of mammalian microRNA targets. Cell 2003, I I 5:787-798.

40. Krek A, Grun D, Poy MN, Wolf R, Rosenberg L, Epstein EJ, MacMenamin P, da Piedade I, Gunsalus KC, Stoffel M, Rajewsky N: Combinatorial microRNA target predictions. Nat Genet 2005, 37:495-500.

4I. Brennecke J, Stark A, Russell RB, Cohen SM: Principles of microRNA-target recognition. PLoS Biol 2005, 3:e85.

42. Xie X, Lu J, Kulbokas EJ, Golub TR, Mootha V, Lindblad-Toh K, Lander ES, Kellis M: Systematic discovery of regulatory motifs in human promoters and 3' UTRs by comparison of several mammals. Nature 2005, 434:338-345.

43. Stark A, Brennecke J, Bushati N, Russell RB, Cohen SM: Animal microRNAs confer robustness to gene expression and have a significant impact on 3'UTR evolution. Cell 2005, 123:1133-1|46.

44. Stark A, Brennecke J, Russell RB, Cohen SM: Identification of Drosophila microRNA targets. PLoS Biol 2003, I:e60.

45. Farh KK, Grimson A, Jan C, Lewis BP, Johnston WK, Lim LP, Burge $C B$, Bartel DP: The widespread impact of mammalian MicroRNAs on mRNA repression and evolution. Science 2005, 310:1817-1821.

46. Rajewsky N, Socci ND: Computational identification of microRNA targets. Dev Biol 2004, 267:529-535.

47. John B, Enright AJ, Aravin A, Tuschl T, Sander C, Marks DS: Human microRNA targets. PLoS Biol 2004, 2:e363.

48. Lall S, Grun D, Krek A, Chen K, Wang YL, Dewey CN, Sood P, Colombo T, Bray N, Macmenamin P, et al.: A genome-wide map of conserved microRNA targets in C. elegans. Curr Biol 2006, 16:460-47I.

49. Miranda KC, Huynh T, Tay Y, Ang YS, Tam WL, Thomson AM, Lim $B$, Rigoutsos I: A pattern-based method for the identification of MicroRNA binding sites and their corresponding heteroduplexes. Cell 2006, I 26: | 203-1217.

50. Miska EA: How microRNAs control cell division, differentiation and death. Curr Opin Genet Dev 2005, I 5:563-568.

5I. Calin GA, Dumitru CD, Shimizu M, Bichi R, Zupo S, Noch E, Aldler $H$, Rattan S, Keating M, Rai K, et al.: Frequent deletions and downregulation of micro-RNA genes $\mathrm{miR} I 5$ and $\mathrm{miR} / 6$ at $\mid 3 \mathrm{q} / 4$ in chronic lymphocytic leukemia. Proc Natl Acad Sci USA 2002, 99:15524-15529.

52. Michael MZ, O'Conner SM, van Holst Pellekaan NG, Young GP, James
RJ: Reduced accumulation of specific microRNAs in colorectal neoplasia. Mol Cancer Res 2003, I:882-891.

53. Murakami Y, Yasuda T, Saigo K, Urashima T, Toyoda H, Okanoue T, Shimotohno K: Comprehensive analysis of microRNA expression patterns in hepatocellular carcinoma and non-tumorous tissues. Oncogene 2006, 25:2537-2545.

54. Jiang J, Lee EJ, Gusev Y, Schmittgen TD: Real-time expression profiling of microRNA precursors in human cancer cell lines. Nucleic Acids Res 2005, 33:5394-5403.

55. Cummins JM, He Y, Leary RJ, Pagliarini R, Diaz LA Jr, Sjoblom T, Barad O, Bentwich Z, Szafranska AE, Labourier E, et al.: The colorectal microRNAome. Proc Natl Acad Sci USA 2006, 103:3687-3692.

56. Lu J, Getz G, Miska EA, Alvarez-Saavedra E, Lamb J, Peck D, SweetCordero A, Ebert BL, Mak RH, Ferrando AA, et al.: MicroRNA expression profiles classify human cancers. Nature 2005, 435:834-838.

57. He L, Thomson JM, Hemann MT, Hernando-Monge E, Mu D, Goodson S, Powers S, Cordon-Cardo C, Lowe SW, Hannon G], Hammond SM: A microRNA polycistron as a potential human oncogene. Nature 2005, 435:828-833.

58. Voorhoeve PM, le Sage C, Schrier M, Gillis AJ, Stoop H, Nagel R, Liu YP, van Duijse J, Drost J, Griekspoor A, et al.: A genetic screen implicates miRNA-372 and miRNA-373 as oncogenes in testicular germ cell tumors. Cell 2006, I24:1|69-1I8I.

59. Johnson SM, Grosshans H, Shingara J, Byrom M, Jarvis R, Cheng A, Labourier E, Reinert KL, Brown D, Slack FJ: RAS is regulated by the let-7 microRNA family. Cell 2005, 1 20:635-647.

60. Mayr C, Hemann MT, Bartel DP: Disrupting the pairing between let-7 and Hmga2 enhances oncogenic transformation. Science 2007, 31 5:1576-1579.

61. Lee YS, Dutta A: The tumor suppressor microRNA let-7 represses the HMGA2 oncogene. Genes Dev 2007, 21:1025-1030.

62. Calin GA, Sevignani C, Dumitru CD, Hyslop T, Noch E, Yendamuri S Shimizu M, Rattan S, Bullrich F, Negrini M, Croce CM: Human microRNA genes are frequently located at fragile sites and genomic regions involved in cancers. Proc Natl Acad Sci USA 2004, 101:2999-3004.

63. Lamy P, Andersen CL, Dyrskjot L, Torring N, Orntoft T, Wiuf C: Are microRNAs located in genomic regions associated with cancer? BrJ Cancer 2006, 95:14I5-14|8.

64. Thomson JM, Newman M, Parker JS, Morin-Kensicki EM, Wright T, Hammond SM: Extensive post-transcriptional regulation of microRNAs and its implications for cancer. Genes Dev 2006, 20:2202-2207.

65. Perou CM, Sorlie T, Eisen MB, van de Rijn M, Jeffrey SS, Rees CA, Pollack JR, Ross DT, Johnsen H, Akslen LA, et al.: Molecular portraits of human breast tumors. Nature 2000, 406:747-752

66. van 't Veer LJ, Dai $H$, van de Vijver MJ, He YD, Hart AA, Mao M, Peterse HL, van der Kooy K, Marton MJ, Witteveen AT, et al.: Gene expression profiling predicts clinical outcome of breast cancer. Nature 2002, 415:530-536.

67. van de Vijver MJ, He YD, van't Veer LJ, Dai H, Hart AA, Voskuil DW, Schreiber GJ, Peterse JL, Roberts C, Marton MJ, et al: A geneexpression signature as a predictor of survival in breast cancer. N Engl J Med 2002, 347:1999-2009.

68. Sotiriou C, Powles TJ, Dowsett M, Jazaeri AA, Feldman AL, Assersohn L, Gadisetti C, Libutti SK, Liu ET: Gene expression profiles derived from fine needle aspiration correlate with response to systemic chemotherapy in breast cancer. Breast Cancer Res 2002, 4:R3.

69. Sorlie T, Tibshirani R, Parker J, Hastie T, Marron JS, Nobel A, Deng S, Johnsen H, Pesich R, Geisler S, et al:: Repeated observation of breast tumor subtypes in independent gene expression data sets. Proc Natl Acad Sci USA 2003, 100:84 I8-8423.

70. Sorlie T, Perou CM, Tibshirani R, Aas T, Geisler S, Johnsen H, Hastie $T$, Eisen MB, van de Rijn M, Jeffrey SS, et al.: Gene expression patterns of breast carcinomas distinguish tumor subclasses with clinical implications. Proc Natl Acad Sci USA 200 I, 98: 10869- I0874.

7I. Paik S, Shak S, Tang G, Kim C, Baker J, Cronin M, Baehner FL, Walker MG, Watson D, Park T, et al: A multigene assay to predict recurrence of tamoxifen-treated, node-negative breast cancer. N Engl J Med 2004, 35 I:2817-2826.

72. Bertucci F, Finetti P, Rougemont J, Charafe-Jauffret E, Cervera N, Tarpin C, Nguyen C, Xerri L, Houlgatte R, Jacquemier J, et al.: Gene expression profiling identifies molecular subtypes of inflammatory breast cancer. Cancer Res 2005, 65:2170-2178.

73. Zhao H, Langerod A, Ji Y, Nowels KW, Nesland JM, Tibshirani R, 
Bukholm IK, Karesen R, Botstein D, Borresen-Dale AL, Jeffrey SS: Different gene expression patterns in invasive lobular and ductal carcinomas of the breast. Mol Biol Cell 2004, I 5:2523-2536.

74. Huang E, Cheng SH, Dressman H, Pittman J, Tsou MH, Horng CF, Bild $A$, Iversen ES, Liao M, Chen CM, et al.: Gene expression predictors of breast cancer outcomes. Lancet 2003, 36I:1590-1596.

75. Ma XJ, Wang Z, Ryan PD, Isakoff SJ, Barmettler A, Fuller A, Muir B, Mohapatra G, Salunga R, Tuggle JT, et al.: A two-gene expression ratio predicts clinical outcome in breast cancer patients treated with tamoxifen. Cancer Cell 2004, 5:607-616.

76. Hu Z, Fan C, Oh DS, Marron JS, He X, Oaqish BF, Livasy C, Carey LA, Reynolds E, Dressler $L$, et al.: The molecular portraits of breast tumors are conserved across microarray platforms. BMC Genomics 2006, 7:96.

77. Iorio MV, Ferracin M, Liu CG, Veronese A, Spizzo R, Sabbioni S, Magri E, Pedriali M, Fabbri M, Campiglio M, et al:: MicroRNA gene expression deregulation in human breast cancer. Cancer Res 2005, 65:7065-7070.

78. Volinia S, Calin GA, Liu CG, Ambs S, Cimmino A, Petrocca F, Visone $\mathrm{R}$, lorio $\mathrm{M}$, Roldo C, Ferracin M, et al.: A microRNA expression signature of human solid tumors defines cancer gene targets. Proc Natl Acad Sci USA 2006, 103:2257-226I.

79. Mattie MD, Benz CC, Bowers J, Sensinger K, Wong L, Scott GK, Fedele V, Ginzinger D, Getts R, Haqq C: Optimized high-throughput microRNA expression profiling provides novel biomarker assessment of clinical prostate and breast cancer biopsies. Mol Cancer 2006, 5:24.

80. Callagy GM, Pharoah PD, Pinder SE, Hsu FD, Nielsen TO, Ragaz J, Ellis IO, Huntsman D, Caldas C: Bcl-2 is a prognostic marker in breast cancer independently of the Nottingham Prognostic Index. Clin Cancer Res 2006, I 2:2468-2475.

8I. Chin SF, Wang Y, Thorne NP, Teschendorff AE, Pinder SE, Vias M, Naderi A, Roberts I, Barbosa-Morais NL, Garcia MJ, et al.: Using array-comparative genomic hybridization to define molecular portraits of primary breast cancers. Oncogene 2007, 26:1959-1970

82. Garcia MJ, Pole JC, Chin SF, Teschendorff A, Naderi A, Ozdag H, Vias M, Kranjac T, Subkhankulova T, Paish C, et al: A I Mb minimal amplicon at $8 \mathrm{plI}-\mathrm{I} 2$ in breast cancer identifies new candidate oncogenes. Oncogene 2005, 24:5235-5245.

83. Naderi A, Teschendorff AE, Barbosa-Morais NL, Pinder SE, Green AR, Powe DG, Robertson JF, Aparicio S, Ellis IO, Brenton JD, Caldas $\mathrm{C}$ : A gene-expression signature to predict survival in breast cancer across independent data sets. Oncogene 2007, 26:1507-1516.

84. Fraley C, Raftery AE: Model-based clustering, discriminant analysis, and density estimation. J Am Stat Assoc 2002, 97:6||-63|

85. Ramaswamy S, Tamayo P, Rifkin R, Mukherjee S, Yeang CH, Angelo M, Ladd C, Reich M, Latulippe E, Mesirov JP, et al:: Multiclass cancer diagnosis using tumor gene expression signatures. Proc Natl Acad Sci USA 200I, 98:15149-15154.

86. van den ljssel P, Tijssen M, Chin SF, Eijk P, Carvalho B, Hopmans E, Holstege H, Bangarusamy DK, Jonkers J, Meijer GA, et al.: Human and mouse oligonucleotide-based array CGH. Nucleic Acids Res 2005, 33:el92.

87. Chin SF, Teschendorff AE, Marioni JC, Wang Y, Barbosa-Morais NL, Thorne NP, Pinder SE, van de Wiel M, Ellis IO, Porter PL, et al.: Highresolution genomic profiling identifies a novel genomic subtype of ER negative breast cancer. Genome Biol 2007, 8:R2 I5.

88. Baskerville S, Bartel DP: Microarray profiling of microRNAs reveals frequent coexpression with neighboring miRNAs and host genes. Rna 2005, I I:24|-247.

89. Obernosterer G, Leuschner PJ, Alenius M, Martinez J: Post-transcriptional regulation of microRNA expression. Rna 2006, 12:1161-1167.

90. Muralidhar B, Goldstein L, Ng G, Winder D, Palmer R, Gooding E, Barbosa-Morais N, Mukherjee G, Thorne N, Roberts I, et al.: Global microRNA profiles in cervical squamous cell carcinoma depend on Drosha expression levels. J Pathol 2007, 21 2:368-377.

91. Eis PS, Tam W, Sun L, Chadburn A, Li Z, Gomez MF, Lund E, Dahlberg JE: Accumulation of miR- 155 and BIC RNA in human $B$ cell lymphomas. Proc Natl Acad Sci USA 2005, 102:3627-3632.

92. Kluiver J, Poppema S, de Jong D, Blokzijl T, Harms G, Jacobs $S$, Kroesen $B$ J, van den Berg $A$ : BIC and miR-I55 are highly expressed in Hodgkin, primary mediastinal and diffuse large
B cell lymphomas. J Pathol 2005, 207:243-249.

93. Si ML, Zhu S, Wu H, Lu Z, Wu F, Mo YY: miR-2I-mediated tumor growth. Oncogene 2006, 26:2799-2803.

94. Peck D, Crawford ED, Ross KN, Stegmaier K, Golub TR, Lamb J: A method for high-throughput gene expression signature analysis. Genome Biol 2006, 7:R6I.

95. Tang F, Hajkova P, Barton SC, Lao K, Surani MA: MicroRNA expression profiling of single whole embryonic stem cells. Nucleic Acids Res 2006, 34:e9.

96. Yu J, Wang F, Yang GH, Wang FL, Ma YN, Du ZW, Zhang JW: Human microRNA clusters: genomic organization and expression profile in leukemia cell lines. Biochem Biophys Res Commun 2006, 349:59-68.

97. Kumar MS, Lu J, Mercer KL, Golub TR, Jacks T: Impaired microRNA processing enhances cellular transformation and tumorigenesis. Nat Genet 2007, 39:673-677.

98. Rhodes DR, Yu J, Shanker K, Deshpande N, Varambally R, Ghosh D, Barrette T, Pandey A, Chinnaiyan AM: ONCOMINE: a cancer microarray database and integrated data-mining platform. Neoplasia 2004, 6: I-6.

99. Neilson JR, Zheng GX, Burge CB, Sharp PA: Dynamic regulation of miRNA expression in ordered stages of cellular development. Genes Dev 2007, 21:578-589.

100. Wheeler DL, Barrett T, Benson DA, Bryant SH, Canese K, Church DM, DiCuccio M, Edgar R, Federhen S, Helmberg W, et al.: Database resources of the National Center for Biotechnology Information. Nucleic Acids Res 2005, 33:D39-45

I0I. Dunning MJ, Thorne NP, Camiler ML, Smith S, Tavaré S: Quality control and low-level statistical analysis of Illumina beadarrays. Revstat 2006, 4:1-30

102. Benjamini $Y$, Hochberg $Y$ : Controlling the false discovery rate: a practical and powerful approach to multiple testing. J Roy Stat Soc B 1995, 57:289-300.

103. van Wieringen WN, Belien JA, Vosse SJ, Achame EM, Ylstra B: ACEit: a tool for genome-wide integration of gene dosage and RNA expression data. Bioinformatics 2006, 22:1919-1920.

104. R Development Core Team: A Language and Environment for Statistical Computing Vienna: R Foundation for Statistical Computing; 2003

105. Gentleman RC, Carey VJ, Bates DM, Bolstad B, Dettling M, Dudoit S, Ellis B, Gautier L, Ge Y, Gentry J, et al.: Bioconductor: open software development for computational biology and bioinformatics. Genome Biol 2004, 5:R80.

106. Gentleman R, Carey VJ, Huber W, Irizarry RA, Dudoit S: Bioinformatics and Computational Biology Solutions Using R and Bioconductor New York: Springer; 2005

107. Fraley C, Raftery AE: MCLUST Version 3 for R: Normal Mixture Modeling and Model-based Clustering Department of Statistics, University of Washington; 2006.

108. Banfield JD, Raftery AE: Model-based Gaussian and non-Gaussian clustering. Biometrics 1993, 49:803-821.

109. Fraley C, Raftery AE: MCLUST: Software for model-based cluster analysis. J Classification 1999, 16:297-306.

1 I0. Fraley C, Raftery AE: Enhanced Software for model-based clustering, discriminant analysis, and density estimation: MCLUST. J Classification 2003, 20:263-286.

III. Wang Y, Klijn JG, Zhang Y, Sieuwerts AM, Look MP, Yang F, Talantov D, Timmermans M, Meijer-van Gelder ME, Yu J, et al.: Gene-expression profiles to predict distant metastasis of lymph-nodenegative primary breast cancer. Lancet 2005, 365:67|-679.

112. Richardson AL, Wang ZC, De Nicolo A, Lu X, Brown M, Miron A, Liao X, Iglehart JD, Livingston DM, Ganesan S: $X$ chromosomal abnormalities in basal-like human breast cancer. Cancer Cell 2006, 9:121-132.

113. Miller LD, Smeds J, George J, Vega VB, Vergara L, Ploner A, Pawitan $Y$, Hall P, Klaar S, Liu ET, Bergh J: An expression signature for p53 status in human breast cancer predicts mutation status, transcriptional effects, and patient survival. Proc Natl Acad Sci USA 2005, 102:13550-13555.

I 14. Gruvberger S, Ringner M, Chen Y, Panavally S, Saal LH, Borg A, Ferno $M$, Peterson C, Meltzer PS: Estrogen receptor status in breast cancer is associated with remarkably distinct gene expression patterns. Cancer Res 200 I, 6 I:5979-5984.

I I5. Chin K, DeVries S, Fridlyand J, Spellman PT, Roydasgupta R, Kuo WL, Lapuk A, Neve RM, Qian Z, Ryder T, et al:: Genomic and transcriptional aberrations linked to breast cancer pathophysiologies. Cancer Cell 2006, 10:529-54I.

116. Ivshina AV, George J, Senko O, Mow B, Putti TC, Smeds J, Lindahl T, Pawitan Y, Hall P, Nordgren H, et al:: Genetic reclassification of 
histologic grade delineates new clinical subtypes of breast cancer. Cancer Res 2006, 66:10292-1030I.

117. Minn AJ, Gupta GP, Siegel PM, Bos PD, Shu W, Giri DD, Viale A, Olshen $A B$, Gerald WL, Massague J: Genes that mediate breast cancer metastasis to lung. Nature 2005, 436:5I8-524.

I 18. Hess KR, Anderson K, Symmans WF, Valero V, Ibrahim N, Mejia JA, Booser D, Theriault RL, Buzdar AU, Dempsey PJ, et al.: Pharmacogenomic predictor of sensitivity to preoperative chemotherapy with paclitaxel and fluorouracil, doxorubicin, and cyclophosphamide in breast cancer. J Clin Oncol 2006, 24:4236-4244.

1 19. Karolchik D, Baertsch R, Diekhans M, Furey TS, Hinrichs A, Lu YT, Roskin KM, Schwartz M, Sugnet CW, Thomas DJ, et al:: The UCSC Genome Browser Database. Nucleic Acids Res 2003, 3 1:5 I-54. 